\title{
Desmopressin for the Treatment of Aspirin-Induced Platelet Dysfunction
}

\author{
Sebastian Schulz-Stübner
}

Published online: 18 August 2010

(C) Springer Science+Business Media, LLC 2010

To the Editor,

Akins et al. [1] describe the role of platelet dysfunction in patients with subdural hematoma formation and highlight this important issue for the treatment of SDH. In their cohort they identified six patients on aspirin with abnormal and six patients on aspirin with normal PFA values. In regard to the therapeutic management of patients with SDH on aspirin I would like to add the option of platelet function enhancement with the application of desmopressin (DDAVP). Given at a dose of $0.03 \mu \mathrm{g} / \mathrm{kg}$ body weight intravenously or intranasally a peak effect with almost normalization of PFA values can be observed within 30 min lasting for about $4 \mathrm{~h}$ in healthy volunteers [2]. Especially when immediate lab results for platelet function are not available empiric treatment for surgery might be warranted for patients on aspirin to provide an optimal time window for surgical evacuation of the hematoma and prevention of rebleeding. Repeated dosing might be necessary if rebleeding occurs. After application of desmopressin urine output should be monitored because water retention is one of the most common side effects using desmopressin for the indication of treatment of aspirin-induced platelet dysfunction.

\section{References}

1. Akins PT, Guppy KH, Hawk MW, Sahrakar K. Slippery platelet syndromes in subdural hematoma. Neurocrit Care. 2010;12: 375-81.

2. Schulz-Stübner S, Zielske D, Rossaint R. Comparison between nasal and intravenous desmopressin for the treatment of acetylsalicylic acid-induced platelet dysfunction. Eur J Anaesthesiol. 2002;19:647-51.
S. Schulz-Stübner $(\bowtie)$

Klinik für Anästhesie und Intensivmedizin, Städtisches Klinikum

Karlsruhe, Moltkestr. 90, 76133 Karlsruhe, Germany

e-mail: schust@t-online.de 